\title{
Hubungan Status Gizi Anak Usia 2-5 Tahun dengan Kelainan Jantung Bawaan Biru di RSUD Dr Soetomo Surabaya
}

\author{
Ayu Pisita Wulandari, Teddy Ontoseno, Pirlina Umiastuti \\ Departemen Ilmu Kesehatan Anak Fakultas Kedokteran Universitas Airlangga/RSUD Dr. Soetomo, Surabaya
}

Latar belakang. Kelainan jantung bawaan biru adalah tipe umum dari kelainan jantung bawaan yang salah satunya disebabkan oleh faktor status gizi. Malnutrisi pada anak dengan kelainan jantung bawaan biru dapat meningkatkan mortalitas dan morbiditas. Tujuan. Untuk menganalisis hubungan status gizi dengan kelainan jantung bawaan biru.

Metode. Penelitian ini menggunakan rancangan observatif cross-sectional. Berat badan, usia, dan jenis kelamin diambil sebagai variabel penelitian. Status gizi dihitung dengan menggunakan metode z-skor dan dibagi menjadi dua kelompok yaitu malnutrisi dan gizi baik. Hasil. Prevalensi kelainan jantung bawaan biru pada anak perempuan adalah 28 anak dan pada anak laki-laki adalah 16 anak. Angka kejadian terbanyak adalah pada anak usia 21-24 bulan. Tetralogi Fallot adalah tipe yang kelainan jantung bawaan biru terbanyak (68,2\% dari total kelainan jantung bawaan biru). Pasien kelainan jantung bawaan biru dengan malnutrisi 63,6\% dan gizi baik 36,4\%. Dengan uji Chi-square diperoleh hubungan yang bermakna secara statistik ( $p=0,007)$ dan hubungan ini pada $\alpha=0,05$ adalah lemah karena koefisien korelasinya sebesar 0,313.

Kesimpulan. Terdapat hubungan yang lemah antara status gizi dengan kelainan jantung bawaan biru pada anak usia 2-5 tahun. Sari Pediatri 2018;20(2):65-9

Kata kunci: kelainan jantung bawaan biru, status gizi, jenis kelamin, usia, berat badan

\section{Correlation between Nutritional Status of 2-5 Years Old Children and Cyanotic Congenital Heart Disease in Dr. Soetomo General Hospital Surabaya}

Ayu Pisita Wulandari, Teddy Ontoseno, Pirlina Umiastuti

Background. Cyanotic congenital heart disease is common congenital heart disease which caused by several factors, include nutritional status. If malnutrition happens in cyanotic congenital heart disease patient, it can increase morbidity and mortality.

Objective. To analyze the correlation of nutritional status in patients with cyanotic congenital heart disease.

Methods. This study was designed in cross-sectional. Weight, age, and sex were taken as variables of the research. The nutritional status was counted using z-score and divided into two groups which are malnutrition and good nutrition.

Results. The prevalence of cyanotic congenital heart disease in girls is 28 childrens and boys is 16 childrens. And mostly common in 21-24 months old of patients. Tetralogy of Fallot is the most common type (68.2\% from total cyanotic patient). The Cyanotic congenital heart disease patient with malnutrion is about $63.6 \%$ and with good nutrition is about $36.4 \%$. These findings suggest that the correlation had significant correlation value $(\mathrm{p}=0.007)$ and this correlation in $\alpha=0.05$ is low because the correlation coefficient is 0.313 .

Conclusion. There a is weak correlation between nutritional status with cyanotic congenital heart disease in 2-5 years old children in this study. Sari Pediatri 2018;20(2):65-9

Keywords: cyanotic congenital heart disease, nutritional status, sex, age, weight

Alamat korespondensi: Ayu Pisita Wulandari. Departemen Ilmu Kesehatan Anak Fakultas Kedokteran Universitas Airlangga/RSUD Dr. Soetomo, Surabaya. Email: ayupisitawulandari@gmail.com 
Ayu Pisita Wulandari dkk: Hubungan status gizi anak usia 2-5 tahun dengan kelainan jantung bawaan biru

$\mathrm{K}$

elainan jantung bawaan adalah tipe kelainan yang paling umum pada bayi baru lahir. Di Amerika Serikat, bayi lahir dengan kelainan . jantung bawaan mendekati $1 \%$ per 40.000 kelahiran setiap tahunnya. ${ }^{1}$ Dari tahun 2012 sampai 2014, terdapat 73.751 bayi diperiksa untuk kelainan jantung dan 857 teridentifikasi memiliki kelainan jantung bawaan. Angka kejadian jantung bawaan biru di Indonesia sendiri masih cukup tinggi, terutama pada anak usia 2-5 tahun. ${ }^{2}$

Kenaikan angka kejadian yang tinggi tersebut dikarenakan belum adanya pengobatan yang memadai. Pengobatan kelainan jantung bawaan biru secara tuntas untuk saat ini hanya dalam bentuk operasi. ${ }^{3}$ Selain itu, kelainan jantung bawaan biru juga dipengaruhi oleh banyak faktor penyulit. Dari banyaknya faktor tersebut, status gizi merupakan salah satu hal penting yang harus diperhatikan. Malnutrisi pada anak dengan kelainan jantung bawaan dapat meningkatkan morbiditas dan mortalitas. Hal ini disebabkan oleh karena anak tersebut akan lebih sering terkena penyakit, ketidakberhasilan operasi, gangguan pertumbuhan, dan peningkatan risiko kematian. ${ }^{4}$

Tujuan dari penelitian ini adalah mengetahui adanya hubungan status gizi anak usia 2-5 tahun dengan kelainan jantung bawaan biru di Instalagi Rawat Jalan Jantung Anak RSUD Dr. Soetomo Surabaya pada tahun 2016.

\section{Metode}

Penelitian ini merupakan penelitian analitik dan menggunakan rancangan observatif cross-sectional untuk mengetahui hubungan status gizi anak usia 2-5 tahun dengan kelainan jantung bawaan biru berdasarkan data rumah sakit.

Sampel penelitian ini adalah total sampling seluruh data rekam medis pasien rawat jalan usia 2-5 tahun dengan diagnosis kelainan jantung bawaan selama periode 2016. Variabel penelitian adalah jenis kelamin, usia dan berat badan pasien. Status gizi anak dihitung berdasarkan metode antropometri z-skor. Digunakan parameter BB/U untuk anak usia 2-5 tahun. Dibagi 2 kelompok, yaitu kelompok gizi baik dan malnutrisi yang terdiri atas gizi lebih, kurang, dan buruk. ${ }^{5} \mathrm{Uji}$ Chi-square digunakan untuk menganalisis hubungan antara status gizi anak usia 2-5 tahun dengan kelainan jantung bawaan biru. Hasil bermakna signifikan bila $\mathrm{p}<0,05$. Semua data dianalisis menggunakan program perangkat lunak SPSS ${ }^{\bullet}$ 16.0.

\section{Hasil}

Jumlah pasien kelainan jantung bawaan dengan usia 2-5 tahun yang melakukan perawatan berjalan di Instalasi Rawat Jalan Jantung Anak RSUD Dr. Soetomo Surabaya selama Januari sampai Desember 2016 tercatat 80 pasien. Penderita dengan kelainan jantung bawaan biru (sianotik) yang memenuhi kriteria inklusi adalah 44 pasien. Karakteristik usia terhadap jenis kelamin penderita kelainan jantung bawaan biru tertera pada Tabel 1.

Jumlah pasien kelainan jantung bawaan biru berjenis kelamin perempuan berjumlah 28 anak (63,6\% dari total sampel). Hal ini lebih banyak dibandingkan pasien berjenis kelamin laki-laki yang berjumlah 16 anak (36,4\% dari total sampel). Kelainan jantung bawaan biru terbanyak terjadi pada rentang usia 21-25 bulan, yaitu total $14(31,8 \%)$ anak. Karakteristik tipe kelainan jantung bawaan biru tertera pada Tabel 2.

Tipe kelainan jantung bawaan biru terbanyak tetralogi fallot yaitu $30(68,2 \%)$ pasien. Atresia pulmonal dengan VSD, atresia trikuspid, dan ebstein anomali masing-masing sama, yaitu $2(4,5 \%)$ pasien. Tipe lainnya, yaitu TGA 7 (15,9\%) dan ventrikel tunggal $1(2,3 \%)$ pasien .

Status gizi anak dihitung menggunakan metode antropometri paremeter BB/U berdasarkan Z-skor untuk anak usia 2-5 tahun yang diklasifikasikan menjadi gizi buruk (<-3SD), gizi kurang (-3SD sampai $<-2 \mathrm{SD})$, gizi baik (-2SD sampai $+2 \mathrm{SD})$, dan gizi lebih $(>+2 \mathrm{SD}) .{ }^{6}$ Pada penelitian ini karena terdapat jumlah sel dengan frekuensi harapan kurang dari 5 lebih dari $20 \%$ maka pembagian status gizi dipersempit menjadi status gizi baik dan malnutrisi. ${ }^{5}$ Status gizi anak dengan kelainan jantung bawaan biru terbanyak adalah malnutrisi $(63,6 \%)$, lebih dari setengah total sampel penelitian. Persentase anak dengan kelainan jantung bawaan biru yang memiliki status gizi baik berjumlah $36,4 \%$. Karakteristik status gizi anak dengan kelainan jantung bawaan biru tertera pada Tabel 3 .

Setelah diketahui karakteristik status gizi anak terhadap kelainan jantung bawaan biru maka dilakukan perhitungan distribusi silang status gizi anak terhadap kelainan jantung bawaan biru. 
Ayu Pisita Wulandari dkk: Hubungan status gizi anak usia 2-5 tahun dengan kelainan jantung bawaan biru

Tabel 1. Distribusi frekuensi kelompok usia anak dengan kelainan jantung bawaan biru

\begin{tabular}{lcccccc}
\hline Usia (bulan) & \multicolumn{2}{c}{ Perempuan } & \multicolumn{2}{c}{ Laki-laki } & \multicolumn{2}{c}{ Total } \\
\cline { 2 - 7 } & $\mathrm{n}$ & $\%$ & $\mathrm{n}$ & $\%$ & $\mathrm{n}$ & $\%$ \\
\hline $21-25$ & 8 & 28,6 & 6 & 37,5 & 14 & 31,8 \\
$26-30$ & 2 & 7,1 & 3 & 18,8 & 5 & 11,4 \\
$31-35$ & 3 & 10,7 & 1 & 6,2 & 4 & 9,1 \\
$36-40$ & 4 & 14,3 & 2 & 12,5 & 6 & 13,6 \\
$41-45$ & 4 & 14,3 & 1 & 6,2 & 5 & 11,4 \\
$46-50$ & 2 & 7,1 & 1 & 6,2 & 3 & 6,8 \\
$51-55$ & 2 & 7,1 & 1 & 6,2 & 3 & 6,8 \\
$56-60$ & 3 & 10,7 & 1 & 6,2 & 4 & 9,1 \\
\hline Total & 28 & 100,0 & 16 & 100,0 & 44 & 100,0 \\
\hline
\end{tabular}

Tabel 2. Distribusi frekuensi tipe kelainan jantung bawaan biru.

\begin{tabular}{lcc}
\hline Tipe kelainan jantung bawaan biru & $\mathrm{n}$ & $\%$ \\
\hline Tetralogi Fallot & 30 & 68,2 \\
Transposisi arteri besar & 7 & 15,9 \\
Ventrikel tunggal & 1 & 2,3 \\
Atresia pulmonal dengan VSD & 2 & 4,5 \\
Atresia tricuspid & 2 & 4,5 \\
Ebstein anomali & 2 & 4,5 \\
\hline Total & 44 & 100,0 \\
\hline
\end{tabular}

Tabel 3. Distribusi silang status gizi anak dengan kelainan jantung bawaan biru.

\begin{tabular}{lcccccc}
\hline Kelainan jantung bawaan & \multicolumn{4}{c}{ Status gizi } & \multicolumn{2}{c}{ Total } \\
\cline { 2 - 6 } & \multicolumn{2}{c}{ Malnutrisi } & \multicolumn{2}{c}{ Gizi baik } & & \\
\cline { 2 - 6 } & $\mathrm{n}$ & $\%$ & $\mathrm{n}$ & $\%$ & $\mathrm{n}$ & $\%$ \\
\hline Biru & 28 & 63,6 & 16 & 36,4 & 44 & 55 \\
Tidak Biru & 11 & 30,6 & 25 & 69,4 & 36 & 45 \\
Total & 39 & 48,8 & 41 & 51,2 & 80 & 100 \\
\hline $\mathrm{p}$ & & & & & & 0,007 \\
\hline
\end{tabular}

Hasil penelitian yang diuji dengan Chi-square menunjukkan hubungan yang bermakna secara statistik dengan $\mathrm{p}<0,05$. Terdapat hubungan yang bermakna antara status gizi dengan kelainan jantung bawaan biru pada $\alpha=0,05$ dengan koefisien korelasi 0,313 yang berarti kekuatan hubungan lemah.

\section{Pembahasan}

Penyebab kelainan jantung bawaan biru dilihat dari faktor lingkungan adalah konsumsi obat teratogenik, penyakit saat hamil, demografi ibu, geografis lingkungan, prematuritas, dan status gizi anak. ${ }^{2,7}$
Status gizi merupakan suatu indikator baik-buruk penyediaan makanan sehari-hari dan menggambarkan keadaan keseimbangan tubuh. Status gizi yang baik diperlukan untuk mempertahankan derajat kebugaran dan kesehatan, serta merupakan komponen penting dalam membantu pertumbuhan bagi anak. ${ }^{8-10}$ Faktor risiko dari kegagalan pertumbuhan pada anak dengan kelainan jantung bawaan antara lain status gizi, left-toright intracardiac shunt (pada kelainan jantung bawaan asianotik), hipertensi pulmonal, dan sianosis. ${ }^{11}$

Gangguan pertumbuhan karena malnutrisi merupakan masalah pada anak dengan kelainan jantung bawaan, terlebih pada kelainan jantung bawaan biru. ${ }^{12}$ Malnutrisi adalah masalah yang biasa 
terjadi pada anak dengan kelainan jantung bawaan biru. ${ }^{4,13}$ Malnutrisi sebenarnya adalah keadaan status gizi yang mencakup gizi buruk, kurang maupun lebih. ${ }^{5}$ Malnutrisi pada anak dengan kelainan jantung bawaan dapat meningkatkan morbiditas dan mortalitas, sebagai indikasi dari sering dirawat di rumah sakit, hasil bedah yang buruk, gangguan pertumbuhan somatik yang terus-menerus dan peningkatan kematian. ${ }^{4}$ Peningkatan kecepatan metabolik sering ditemukan pada anak dengan kelainan jantung bawaan, dan energi total pada anak dengan kelainan jantung bawaan $40 \%$ lebih tinggi dibandingkan dengan anak sehat. ${ }^{14}$

Hasil penelitian menggunakan uji Chi-square didapatkan hasil yang bermakna perbedaan status gizi pada pasien kelainan jantung bawaan antara yang biru dan tidak biru . Pada pasien dengan kelainan jantung bawaan biru terdapat $63,6 \%$ pasien dengan status gizi malnutrisi. Sementara pasien kelainan jantung bawaan tidak biru yang memiliki status gizi malnutrisi hanya 30,6\%. Gizi kurang terjadi pada lebih dari 50\% anak dengan kelainan jantung bawaan biru dan merupakan salah satu penyulit terbanyak pada kelompok kelainan jantung bawaan biru. ${ }^{2}$ Pasien dengan kelainan jantung bawaan biru biasanya mengalami keterlambatan pertumbuhan yang lebih parah daripada pasien dengan kelainan jantung bawaan tidak biru. ${ }^{14}$ Pasien dengan kelainan jantung bawaan biru tipe tetralogi fallot sering mengalami gizi kurang dan hal ini merupakan faktor penyulit dari tetralogi fallot, sedangkan pasien kelainan jantung bawaan biru tipe TGA lebih sering ditemukan berat badan normal atau lebih. ${ }^{2}$

Kelainan jantung bawaan biru merupakan salah satu faktor risiko terjadinya malnutrisi pada pasien kelainan jantung bawaan. ${ }^{2}$ Pasien dengan kelainan jantung bawaan biru biasanya menunjukkan berat badan dan tinggi badan yang kurang dari anak seusianya. ${ }^{15}$ Kedua hal tersebut juga akan memengaruhi status gizi anak. Basal metabolite rate (BMR) jantung pada anak dengan kelainan jantung bawaan biru lebih tinggi daripada anak dengan kelainan jantung bawaan tidak biru. ${ }^{16}$

Berat, panjang, dan lingkar kepala adalah ukuran dan tanda pada grafik pertumbuhan untuk membantu mengidentifikasi kegagalan pertumbuhan. Penurunan persentil berat dibanding lingkar kepala juga merupakan tanda meningkatnya risiko kelainan jantung. Hambatan pertumbuhan jasmani anak diakibatkan kelainan jantung bawaan. Secara fisik, yang terhambat adalah berat badan dari pada tinggi badan.
Berat badan pasien tidak jarang ada di bawah persentil 3 , sedangkan tinggi badan masih normal atau sedikit di bawah normal. Mekanisme terjadinya gangguan pertumbuhan karena malnutrisi pada kelainan jantung bawaan disebabkan oleh banyak faktor, antara lain, asupan kalori yang tidak adekuat, gangguan pencernaan makanan (malabsorbsi), besarnya defek, infeksi, pengaruh obat jantung, intoleransi makanan, dan pengaruh hormon pertumbuhan. ${ }^{2}$

Anak dengan kelainan jantung bawaan biru ditandai dengan aliran darah pulmoner yang tidak cukup sehingga menyebabkan oksigenasi pada sistem darah arteri berkurang. ${ }^{15}$ Pada anak dengan kelainan jantung bawaan biru didapatkan kelainan struktur dan fungsi jantung sedemikian rupa sehingga sebagian atau seluruh darah balik vena sistemik yang mengandung darah rendah oksigen kembali beredar ke sirkulasi sistemik. Terdapat aliran pirau dari kanan ke kiri atau terdapat percampuran darah balik vena sistemik dan vena pulmonalis. Pada pasien dengan kelainan jantung bawaan biru, darah yang miskin oksigen mengalir ke dalam sirkulasi sistemik dan menyebabkan hipoksemia arterial. ${ }^{17}$ Hipoksemia ini menyebabkan malnutrisi, berupa gangguan pada pencapaian berat badan dan tinggi badan pada anak dengan kelainan jantung bawaan biru. ${ }^{18,19}$ Sesak napas dan napas cepat menyebabkan anak mudah lelah yang kemudian dapat menurunkan nafsu makan serta kemampuan konsumsi makanan dalam jumlah cukup.

Anak kelainan jantung bawaan biru yang mengalami hipoksia kronis disebabkan oleh saturasi oksigen yang rendah. Hal tersebut juga berhubungan dengan terjadinya malnutrisi. Kadar glukosa puasa juga cenderung lebih rendah serta terdapat peningkatan rata-rata sekresi insulin. Kondisi hipoglikemia kronis ini menyebabkan kelelahan saat makan. ${ }^{2}$

\section{Kesimpulan}

Terdapat hubungan yang lemah antara status gizi anak usia 2-5 tahun dengan kelainan jantung bawaan biru.

\section{Daftar pustaka}

1. Centers for Disease Control and Prevention. Data and statistics congenital heart defects. United States: CDC; 2016.

2. Ontoseno T. Penyakit jantung bawaan di Indonesia dan 
kaitannya dengan sumber daya manusia yang berkualitas. Penerimaan Jabatan Guru Besar dalam bidang Ilmu Kesehatan Anak; FK Unair, Surabaya; 19 Maret 2010. Surabaya: 2010.

3. Ontoseno T. Buku ajar kardiologi anak penyakit jantung bawaan sianosis. Surabaya: Airlangga University Press; 2014.

4. Okoromah CA, Ekure EN, Lesi FE, Okunowo WO, Tijani BO, Okeivi JC. Prevalence, profile and predictors of malnutrition in children with congenital heart defects: a casecontrol observational study. Arch Dis Child 2011;96:354-60.

5. Revonadi Y dan Garcia S. Malnutrisi dan mitos kehamilan (studi tentang kemiskinan dan pantang selama masa kehamilan pada ibu hamil yang BBLR di Teluk Betung Barat, Bandar Lampung). Lampung: Digital Repisatory Unila; 2013.

6. Haq FU, Jalil F, Hashmi S, dkk. Risk factors predisposing to congenital heart defects. Annals of Pediatric Cardiology. Ann Pediatr Cardiol 2011;4:117-21.

7. Kementrian Kesehatan Republik Indonesia. Buku antropometri penilaian status gizi anak. Jakarta: Kemkes RI; 2010

8. Irianto DP. Panduan gizi lengkap keluarga dan olahragawan. Yogyakarta: Penerbit Andi; 2007.

9. Amosu, Degun. International academic journals and conference - allied academies. Alliedacademies; 2014.

10. Badake QD, Maina I, Mboganie MA, dkk. Nutritional status of children under five years and associated factors in Mbeere South District, Kenya. Afrika: African Crop Science Society 2014;22;799-806.

11. Dalili M, Meraji SM, Davari P, Moghaddam MY, Abkenar HB, Vahidi A, Shahmohammadi A. Growth status of Iranian children with hemodynamically important congenital heart disease. Acta Med Iran 2011;49:103-8.

12. Costello CL, Gellatly M, Daniel J, Justo RN, Weir K. Growth restriction in infants and young children with congenital heart disease. Congenit Heart Dis 2015;10:447-56.

13. Hassan BA, Albanna EA, Morsy SM, dkk. Nutritional status in children with un-operated congenital heart disease: An Egyptian Center Experience. Front Pediatr 2015;15;3:53.

14. Kumala EEI. Perbedaan status gizi pada anak dengan penyakit jantung bawaan sianotik dan asianotik. Jurnal Media Medika Muda. Semarang: Universitas Diponegoro, 2012. Diakses pada 26 Juli 2018. Didapat dari: http://download.portalgaruda.org/ article.php? article $=73777$ o val $=4695$

15. Samour P, Helm K. Handbook of pediatric nutrition. Sudbury, Mass: Jones and Bartlett; 2005.h.407-17.

16. Modi P, Suleiman MS, Reeves BC, Pawade A, Parry AJ, Angelini GD, dkk. Basal metabolic state of hearts of patients with congenital heart disease: the effects of cyanosis, age, and pathology. PubMed-NCBI. Ann Thorac Surg 2004;78:1710-6.

17. Rose SS, Shah AA, Hoover DR, Saidi P. Cyanotic congenital heart disease (CCHD) with Symptomatic Erythrocytosis. J Gen Intern Med 2007;22:1775-7.

18. Shrivastava S. Malnutrition in congenital heart disease. Indian Pediatr 2008;45:535-6.

19. Irving, S. Patterns of weight change in infants with congenital heart disease following neonatal surgery: potential predictors of growth failure, (disertasi). Pennsylvania: University of Pennsylvania, 2011. 